MICHAEL DIETER

\section{hack the system!}

\begin{tabular}{l}
\hline MCKENZIE WARK \\
\hline A Hacker Manifesto \\
\hline Harvard University Press, Cambridge, 2004 \\
\hline ISBN 0-674-01543-6 \\
\hline RRP US\$21.95 (pb) \\
\hline
\end{tabular}

Prior to being associated closely with criminality and terrorism, hacking was predominantly known as a form of amateur or DIY experimentalism. Originally, the term was used to describe a process of technological 'trial and error' that pretty much defined the early history of personal computing. From phone phreaking to modifying code and soldering integrated circuitry at home, hackers tested the limits of informational systems and remodelled technology for their own unorthodox use. According to the legends, such exploratory activities were not simply carried out as an innocent hobby or pastime-in Hackers: Heroes of the Computer Revolution, Stephen Levy most famously characterised the original programmers at MIT as anarchistically distrustful of authority, vehemently supportive of decentralisation and committed to the complete and unlimited access to data. Invariably, this belief system required a certain degree of anticommercialism (no doubt inspired by the academic gift economy from which such technologies emerged), as intellectual property was perceived to lock down code, limit innovation and restrict the overall quality of work being done. Hacking was, therefore, conveyed ideologically as a form of 'freedom fighting', a practice conducted under a libertarian ethic later encapsulated by Stewart Brand's now infamous mantra: 'information wants to be free'.

Traces of this foundational era currently inform the present, now deeply embedded in cyber-folklore and mobilised by online movements against the privatisation of the Net, like open source GNU/Linux, the Creative Commons licensing system or development of what 
Geert Lovink has labelled 'critical Internet theory'. As a dynamic critique of intellectual property, A Hacker Manifesto is produced in dialogue with such initiatives-quite literally, being composed through McKenzie Wark's participation with the collaborative mailing list nettime. The influence is manifest in style, with the book resembling a mash of hacker myth and a so-called 'cypto-Marxist' tradition, which includes Walter Benjamin, Guy Debord and Gilles Deleuze, among a host of other influential thinkers. Provocatively, the structure is aphoristic, presented in tightly condensed stanzas reminiscent of Debord's The Society of the Spectacle, with modified quotations from Karl Marx (taken as 'source code') or Jacques Rousseau sprinkled throughout-for example, 'information wants to be free but is everywhere in chains'. (126) In a final conceptual twist, the text has been taken on the character of an adaptive 'work in progress', with several versions being made available online and remodelled through a process of peer consultation; each addition expanding out from the last like a software update or remixed dubplate. While this latest physical publication from Harvard University Press is not necessarily the complete transcript, it does include an exclusive and fascinating annotated bibliography.

In terms of content, however, A Hacker Manifesto moves well beyond computer systems and code by applying an expansive definition of hacking as any form of work engaged in the pursuit of intellectual endeavor. Through this rationale, researchers, biologists, chemists, programmers, authors, artists, musicians and the like are all perceived as potential hackers, each sharing convergent interests in the production of 'new concepts, new perceptions, new sensations, hacked out of raw data'. (2) Moreover, according to Wark, such creative commonality is politicised as immaterial labour becomes coopted by an invasive monopoly of intellectual property rights. Here, the ongoing conflict over copyright and patent legislation is dramatised as an epic struggle with the ruling 'vectoralist' class_an insidious elite controlling the means of distribution (presumably, the Walt Disney Company, Microsoft, News Corporation, and so on).

Keeping with the Marxist analytical framework, this contemporary class war is portrayed as the historical culmination of three successive waves of commodification, each based on the social expansion of property rights (the invention of which represents the most influential and expansive hack). The first period involves the privatisation of land, the second centres on the production of goods, while the final stage is characterised by the emergence of information in the commodity form. Despite seeming continuous, however, this third stage is unique due to the particular 'non-rivalous' nature of datainformation is an asset that can be potentially shared without reducing any inherent benefits. To take the classic example, if I download an MP3, I make an additional copy of the file, rather than taking a song away from you-in this case, more is more. Such is the viability of an alternative gift economy, a genuine rival to the socially alienating market of capital. Along this logic, therefore, the hacker class can drive capital into a state of hypertrophy through the subversive innovation and distribution of new 
concepts-a dynamic that takes the form of expressive politics. Like all great manifestos, there is a definite utopian inclination to its vision: 'expressive politics becomes a viable politics only at the moment when a class arises which can not only conceive of freedom from property as its class interest, but propose to the producing classes that it is in the interests of the producing classes as a whole'. (256)

From a strictly critical perspective, however, the conception of class used throughout A Hacker Manifesto is somewhat problematic. The collective lumped together under the rubric of 'hacking' ultimately represents a radically diverse social group, situated asymmetrically across the means of production. At worst, this model reiterates the same conceptual naivety of Richard Florida's creative class. A more generous comparison, however, might be Antonio Negri and Michael Hardt's conception of the democratic 'multitude', that is, the formation of collaborative networks equally based on autonomy and solidarity via partnerships formed by immaterial labor. This theorisation is partly inspired by the recent alternative globalisation movement (compellingly, Wark links this political manifestation to the 'revolts of 1989' and collapse of socialist Europe). While the idealism of this theoretical model is admirable, certain problems with decentralised 'class' structures tend to get glossed over in their articulation, in particular, the tendency to remain radically contingent and politically ambiguous. As critiques of 'the Battle of Seattle' demonstrate, for instance, the weakness of the distributed network model allowed dangerous precedents for far-right influence over progressive dis- course and activism. Additionally, alliancebased multitudes have proven notably resistant to effective consensus building, evident in the slow articulation of policy at the World Social Forum. Attempting to unite 'hackers' through such a liminal class formation seems hopelessly ambitious, even considering examples of online peer-to-peer cultures in networked concert. This is a symptom of A Hacker Manifesto as a whole; the ethereal imaginary of cyberspace is extrapolated as primary and universal, obscuring material and very real conditions on the ground in the process.

Interestingly, Wark includes a chapter on education as 'slavery', synthesising the distrust of rote knowledge in hacker communities with recent publications like Stanley Aronowitz's The Knowledge Factory on the commercialised state of higher learning. In this section, the administration of knowledge at a tertiary level is linked to a broader critique of the information economy as a whole, so university education becomes a product that 'enchains the mind and makes it a resource for class power'. (48) While such rhetoric may well resonate with the current Australian political climate, particularly the trend toward deregulation marked by the Nelson reforms and the proposed Optional Membership of Student Organisations legislation, it's quite a striking riff in the context of a 'little red book' published by Harvard University Press. Elsewhere, Wark has described this seditious passage as an appeal to every 'hipsterslacker student' out there, and this is obviously a goal of the project as a whole (beware, you are a target market). Now, I'm hardly one to take up banal nitpicking of apparent inconsistencies 
in any political vision, but perhaps the 'vectorisation' of the text itself illustrates the extent to which A Hacker Manifesto remains problematically utopian. Possibly, the call for a radical revolution from the hacker class is not the most realistic strategy to counter the current globalising juggernaut of capital-itself far more collaborative, distributive and sustainable than any activist network now in operation. Such entangled polemics are no doubt inescapable; however, to my mind, political intervention ultimately requires a more pragmatic approach, a constructive strategy to which Wark's revolutionary treatise can only remain a part.

MICHAEL DIETER is a PhD candidate in cultural studies, Department of English, University of Melbourne. 